\title{
SÍNTESE DE CATALISADORES Pt@Sb/C PARA O OXIDAÇÃo ELETROQUÍMICA DE METANOL EM MEIO ÁCIDO
}

\author{
M. A. SANTOS ${ }^{1}$, L. S. R. SILVA ${ }^{1}$, K. I. B. EGUILUZ ${ }^{2}$, G. R. SALAZAR-BANDA ${ }^{2}$ \\ ${ }^{1}$ Universidade Tiradentes, Instituto de Tecnologia e Pesquisa. \\ ${ }^{2}$ Universidade Tiradentes, Instituto de Tecnologia e Pesquisa, Departamento de \\ Engenharia de Processos. \\ mychelliandrade@gmail.com
}

\begin{abstract}
RESUMO - Nas células a combustível de metanol direto o uso de nanocatalisadores do tipo casca-núcleo é uma alternativa promissora à Pt pura. Assim, foram sintetizados catalisadores casca-núcleo de $\mathrm{Pt} @ \mathrm{Sb} / \mathrm{C}$ nas proporções 3:1 e 2:1 utilizando o boridreto de sódio como agente redutor. Esses catalisadores foram submetidos à caracterização eletroquímica, e mostram-se condizentes com a estrutura casca-núcleo, devido à similaridade dos seus perfis com o comportamento típico da Pt policristalina em meio ácido (relacionado às regiões de adsorção e dessorção de hidrogênio e a formação de óxidos de Pt). Além disso, nas reações de oxidação do metanol os catalisadores cascanúcleo apresentaram altas densidades de corrente, com potenciais de início de oxidação entre $0,56 \mathrm{~V}$ e $0,59 \mathrm{~V}(3: 1$ e $2: 1$, respectivamente). $\mathrm{O} \mathrm{Pt} / \mathrm{C}$ obteve uma atividade eletrocatalítica $62 \%$ inferior na oxidação de metanol comparado ao PtSb (3:1), tornando este último promissor para aplicações futuras em células a combustível.
\end{abstract}

\section{INTRODUÇÃO}

A crescente demanda de energia e o alto índice de poluição, provocado pelo uso de combustíveis fósseis, principalmente em veículos automotores, desperta a atenção da comunidade científica para a busca por fontes energéticas renováveis de baixo impacto ambiental e que estejam de acordo com a necessidade da manutenção dos recursos naturais (Debe, 2012; Falin et al., 2007).

Uma alternativa altamente promissora de elevada eficiência e principalmente ecologicamente correta são as células a combustível. Célula a combustível é um dispositivo eletroquímico que converte continuamente energia química de um combustível diretamente em energia elétrica e térmica, de maneira mais ecológica e eficiente (Scachetti, 2007).

Estudos a respeito da oxidação de combustíveis orgânicos com o uso de eletrocatalisadores nanométricos vêm demonstrando excelentes resultados e merecem maior aprofundamento pela possibilidade de impetrar viabilidade técnica ao funcionamento de dispositivos eletroquímicos, geradores de energia. Desta forma, uma célula a combustível que utiliza um álcool diretamente como combustível - DAFC (do inglês: - Direct Alcohol Fuel Cell) tem despertado bastante 


\section{9 a 22 de outubro de 2014 \\ Florianópolis/SC}

interesse, particularmente aquelas que são alimentadas pelos combustíveis, metanol, etanol e principalmente glicerol (Roquet et al., 1994).

A célula a combustível de metanol direto (DMFC) é uma variação da PEMFC (do inglês: Proton Exchange Membrane Fuel Cell) na qual o metanol é aplicado diretamente no eletrodo da célula sem a necessidade de reforma do combustível para se ter hidrogênio puro, não requerendo um reformador externo. Além disso, o metanol é uma opção atrativa de combustível porque pode ser produzido a partir do gás natural ou de fontes renováveis como a biomassa (Antoniassi, 2006).

Os metais M (Mn, Sb e Sn) constituem fases intermetálicas estáveis com a platina (Moffatt, 1976; Massalski, 1990), por gerarem espécies oxigenadas na superfície eletródica em soluções ácidas a potenciais menos positivos do que a platina pura e, por apresentarem um bom desempenho para a oxidação de álcoois em meio ácido quando depositados sobre superfície de Pt.

Embora os eletrodos de metais nobres apresentem uma limitação econômica para o emprego em escala industrial, ainda parecem ser os mais indicados quando empregados juntamente com metais não nobres para o estudo introdutório de problemas relacionados à oxidação de álcoois. Assim, a fim de se desenvolver um eletrocatalisador eficiente diminuindo a quantidade de Pt (metal nobre) utilizada, efetua-se a adição de outros metais juntamente com a platina, formando ligas, co-depósitos e estruturas casca-núcleo (García-Contreras et al., 2008; Lee e Doo, 2009). Esse tipo de estrutura, denominada casca-núcleo são nanopartículas que possuem átomos de catalisador somente do lado de fora (Zhang et al., 2005). As partículas são normalmente sintetizadas num processo de dois passos. Em primeiro lugar, o núcleo (Sb neste caso) é sintetizado utilizando estabilizantes contendo funcionalidades que se ligam a um segundo metal. Deste modo, uma segunda solução precursora onde contém o metal (normalmente a Pt) é adicionada, que sintetiza a casca, ou seja, que recobre o núcleo.

Desta forma, a proposta do presente trabalho de pesquisa consistiu no estudo de duas diferentes composições de catalisadores casca-núcleo com metais nobres ( $\mathrm{Pt}$ e $\mathrm{Sb}$ ) ao suporte de carbono, visando criar novas estruturas de catalisadores para ânodos de DAFC's e acima de tudo, que sejam capazes de oxidar álcoois primários e até mesmo secundários com rápida cinética e desativação tolerável. Portanto, neste trabalho foi feito o estudo da eletro-oxidação de metanol sobre a superfície de nanopartículas casca-núcleo, preparadas pelo método de redução de sucessiva, na tentativa de desenvolver materiais altamente ativos e estáveis, almejando em um futuro próximo, aplicá-los em células a combustível alimentadas diretamente com metanol.

\section{OBJETIVO}

Sintetizar catalisadores casca-núcleo $\mathrm{Pt}_{x} @ \mathrm{Sb}_{y}$ suportados em carbono, e analisar a influência das condições de síntese e da composição do catalisador na atividade eletrocatalítica frente as reações de oxidação de metanol em meio ácido, visando desenvolver catalisadores para 
uso em ânodos de células a combustível de álcool direto.

\section{METODOLOGIA}

\subsection{Síntese dos eletrocatalisadores nanoestruturados}

O método de síntese do eletrocatalisador tem uma influência importante na eficiência eletrocatalítica do mesmo, pois afeta a composição final, assim como a estrutura da superfície dos catalisadores, o qual pode alterar a atividade catalítica. Todos os catalisadores sintetizados neste trabalho foram obtidos com $20 \%$ em massa de metal em relação ao carbono Vulcan XC72. As amostras casca-núcleo foram identificadas, como: $\mathrm{Pt}_{3} @ \mathrm{Sb} / \mathrm{C}$ e $\mathrm{Pt}_{2} @ \mathrm{Sb} / \mathrm{C}$. Os eletrocatalisadores casca-núcleo $\mathrm{Pt} @ \mathrm{Sb} / \mathrm{C}$ com razão atômica $(2: 1)$ e (3:1) foram sintetizados pelo método de redução sucessiva, tanto para produção da casca de Pt como para a preparação de nanopartículas de antimônio que compõem o núcleo. O método de síntese utilizado no trabalho utilizou o boridreto de sódio como agente redutor. As nanopartículas de $\mathrm{Sb}$ e $\mathrm{Pt}$ foram reduzidas e estabilizadas por dissolução dos precursores metálicos $\mathrm{SbCl}_{3}$ e $\mathrm{H}_{2} \mathrm{PtCl}_{6} \cdot 6 \mathrm{H}_{2} \mathrm{O}$.

Inicialmente $\mathrm{O}_{\mathrm{SbCl}_{3}}$ foi dissolvido em fase líquida aquosa de $\mathrm{HCl}$ a $5 \mathrm{~mol} \mathrm{~L}^{-1}$, e esta submetida a agitação durante 25 min para dissolução dos íons metálicos. Em seguida adicionouse 33 gotas de $\mathrm{NH}_{4} \mathrm{OH}$ para ajustar o $\mathrm{pH}$ da solução entre 9 e 10 . O boridreto foi adicionado à solução convertendo o precursor metálico (em estado iônico) em átomos metálicos, que se agregaram formando as nanopartículas de Sb. A solução núcleo foi submetida à agitação de 100 rpm durante $1 \mathrm{~h}$. $\mathrm{O} \mathrm{H}_{2} \mathrm{PtCl}_{6} \cdot 6 \mathrm{H}_{2} \mathrm{O}$ foi dissolvido em solução de $\mathrm{HCl} 5 \mathrm{~mol} \mathrm{~L}{ }^{-1}$ separadamente e adicionado à solução do núcleo de forma rápida. Em seguida adicionou-se 97 gotas de $\mathrm{NH}_{4} \mathrm{OH}$ para ajustar o pH da solução. Num segundo estágio o boridreto foi adicionado para redução dos íons de $\mathrm{Pt}$ sobre as nanopartículas de $\mathrm{Sb}$ formadas em etapa prévia. A solução casca-núcleo esteve sujeita à agitação de $100 \mathrm{rpm}$ durante $1 \mathrm{~h}$ ou até a solução tornar-se límpida, garantindo ausência do íon cloreto, e consequente formação das nanopartículas metálicas em suspensão de pó de carbono. A solução foi mantida em agitação final por $24 \mathrm{~h}$ para o ancoramento das nanopartículas no carbono. Em seguida, a suspensão foi centrifugada a $3000 \mathrm{rpm}$ por 20 min e posteriormente lavada e filtrada a vácuo e mantida em estufa a $70^{\circ} \mathrm{C}$ por $3 \mathrm{~h}$ para evaporação do solvente.

\subsection{Preparação do eletrodo de trabalho}

Os eletrodos de trabalho estavam compostos pelas nanopartículas metálicas na forma de uma camada fina sobreposta a uma placa de diamante dopado com boro (DDB). Para a preparação da camada catalítica para cada eletrocatalisador, uma suspensão aquosa foi produzida por dispersão de $0,008 \mathrm{~g}$ do compósito metal/C em solução de Nafion ${ }^{\circledR} 0,5 \%$ (Aldrich ${ }^{\circledR}$, solução a $5 \%$ em álcoois alifáticos) mais $1000 \mu \mathrm{L}$ de água ultrapura (sistema MILLI-Q), seguida de agitação em ultrassom de banho UNIQUE 1450 com um mínimo de duração de 40 min, até a formação de uma espécie de "tinta preta homogênea". Posteriormente, uma alíquota de $30 \mu \mathrm{L}$ desta suspensão foi transferida para a superfície do eletrodo de DDB, de forma a recobrir toda a 
sua área superficial. Finalmente o eletrodo foi colocado em estufa (SOLAB) a $60{ }^{\circ} \mathrm{C}$, para evaporação dos solventes, por aproximadamente $20 \mathrm{~min}$.

\section{RESULTADOS E DISCUSSÃO}

\subsection{Caracterização eletroquímica}

\subsubsection{Voltametria Ciclíca}

Inicialmente na caracterização eletroquímica, foram realizados experimentos para a obtenção dos perfis voltamétricos dos eletrocatalisadores $\mathrm{Sb} / \mathrm{C}$ e da $\mathrm{Pt} / \mathrm{C}$ preparados por redução sucessiva com o objetivo de realizar uma comparação das suas propriedades eletroquímicas com os catalisadores casca-núcleo $\mathrm{Pt}_{2} @ \mathrm{Sb} / \mathrm{C}$ e $\mathrm{Pt}_{3} @ \mathrm{Sb} / \mathrm{C}$.
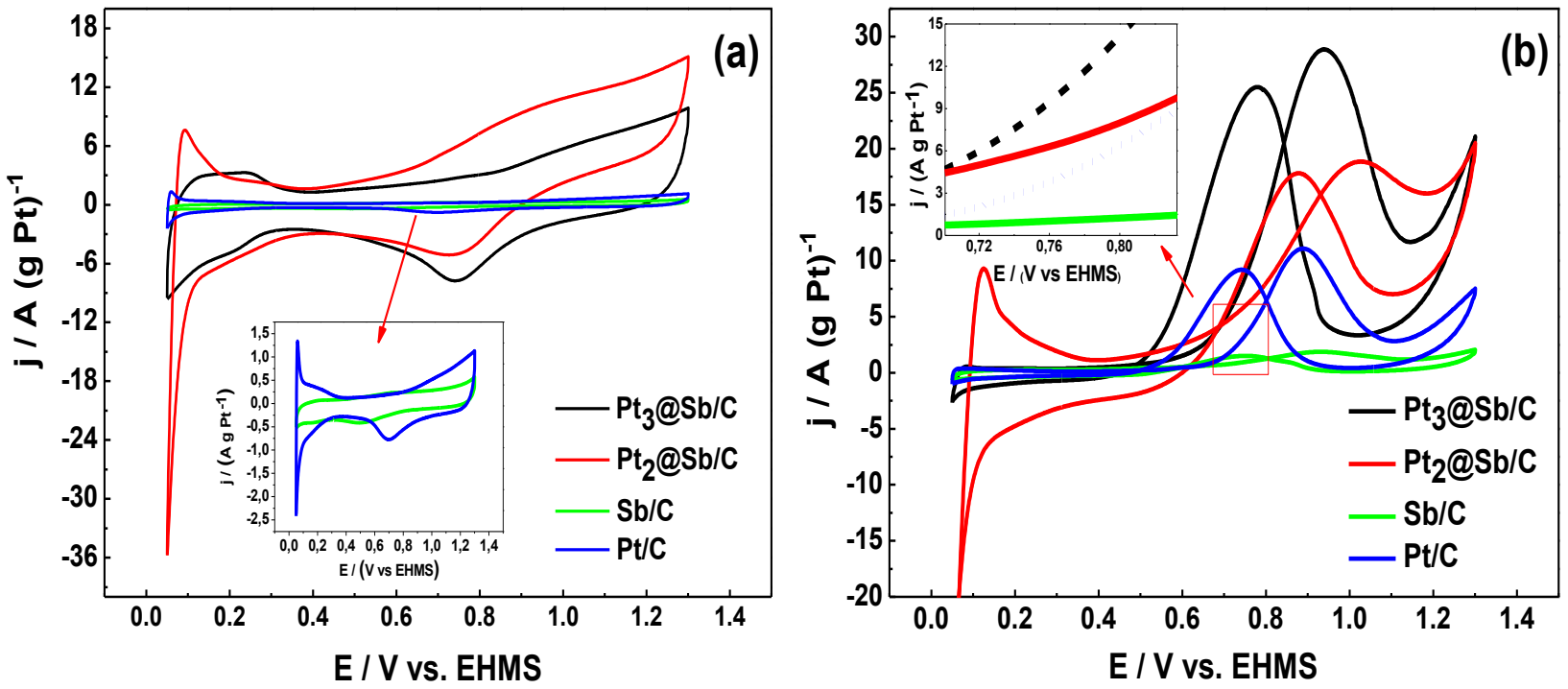

Figura 1 (a) - Perfils voltamétricos para os eletrocatalisadores $\mathrm{Pt}_{3} @ \mathrm{Sb} / \mathrm{C}, \mathrm{Pt}_{2} @ \mathrm{Sb} / \mathrm{C}, \mathrm{Sb} / \mathrm{C}$ e Pt/C em solução de $5 \mathrm{~mol} \mathrm{~L}^{-1}$ de $\mathrm{H}_{2} \mathrm{SO}_{4}$ e (b) Perfils voltamétricos para os eletrocatalisadores $\mathrm{Pt}_{3} @ \mathrm{Sb} / \mathrm{C}, \mathrm{Pt}_{2} @ \mathrm{Sb} / \mathrm{C}, \mathrm{Sb} / \mathrm{C}$ e Pt/C em solução de 5 mol L ${ }^{-1}$ de $\mathrm{H}_{2} \mathrm{SO}_{4}+5$ mol L ${ }^{-1}$ de metanol.

Pode-se observar na Figura 1(a) que os perfis voltamétricos dos eletrocatalisadores $\mathrm{Pt}_{3} @ \mathrm{Sb} / \mathrm{C}$ e $\mathrm{Pt}_{2} @ \mathrm{Sb} / \mathrm{C}$ mostraram-se condizentes com estruturas casca-núcleo, especialmente o $\mathrm{Pt}_{3} @ \mathrm{Sb} / \mathrm{C}$, isto devido à similaridade do seu perfil com o comportamento típico da $\mathrm{Pt}$ policristalina em meio ácido (aumento nas regiões de adsorção e dessorção de hidrogênio e a formação de óxidos). Foi claramente observável que não houve nenhum tipo de deslocamento do pico de redução de oxigênio para potenciais mais negativos na amostra casca-núcleo, mostrando que não há $\mathrm{Sb}$ em contato com a solução, pois a redução de oxigênio se dá em potenciais menos positivos neste material (curva verde). 


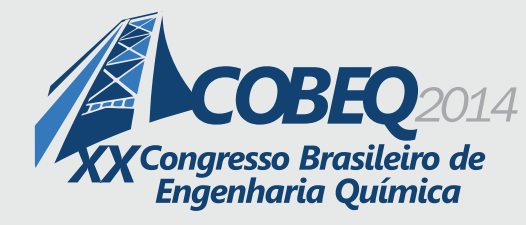

19 a 22 de outubro de 2014

Florianópolis/SC

Para todas as combinações casca-núcleo estudadas, foi observado que o voltamograma obtido para amostra $\mathrm{Pt}_{3} @ \mathrm{Sb} / \mathrm{C}$ apresentou picos anódicos e catódicos mais pronunciados na região compreendida entre 0,05 e 0,35 V vs. EHMS (eletrodo de hidrogênio preparado com a mesma solução) em comparação com a composição de $\mathrm{Pt}_{2} @ \mathrm{Sb} / \mathrm{C}$. Atribui-se que picos bem definidos nesta região resultam da dessorção de átomos de hidrogênio provenientes de sítios de Pt com rede cristalina bem definida, e partículas com tamanhos menores (Tamizhmani et al., 1996; Salgado e Gonzalez, 2003).

Analisando-se os perfis voltamétricos na Figura 1 (b) podemos observar que o processo da reação do metanol tanto para os eletrocatalisadores $\mathrm{Pt} / \mathrm{C}$ e $\mathrm{Sb} / \mathrm{C}$ como para os eletrocatalisadores casca-núcleo $\mathrm{Pt}_{3} @ \mathrm{Sb} / \mathrm{C}$ e $\mathrm{Pt}_{2} @ \mathrm{Sb} / \mathrm{C}$ apresentaram picos bem definidos tanto na varredura positiva como na varredura negativa. Pode-se observar um deslocamento para valores menos positivos do potencial de início de oxidação entre $0,7 \mathrm{~V}$ e $0,74 \mathrm{~V}$ para os eletrocatalisadores $\mathrm{Pt}_{3} @ \mathrm{Sb} / \mathrm{C}$ e $\mathrm{Pt}_{2} @ \mathrm{Sb} / \mathrm{C}$, respectivamente, em relação ao eletrocatalisador $\mathrm{Pt} / \mathrm{C}$ 0,79 $\mathrm{V}$, fato que sugere uma menor energia necessária para a oxidação do combustível. Também pode ser observado uma pseudo-densidade de corrente de pico superior 28,87 A (g Pt) $)^{-1}$ e 18,84 A (g Pt) para os eletrocatalisadores $\mathrm{Pt}_{3} @ \mathrm{Sb} / \mathrm{C}$ e $\mathrm{Pt}_{2} @ \mathrm{Sb} / \mathrm{C}$ em relação aos eletrocatalisadores Sb/C 1,85 A $(\mathrm{g} \mathrm{Pt})^{-1}$ e $\mathrm{Pt} / \mathrm{C} 11,08 \mathrm{~A}(\mathrm{~g} \mathrm{Pt})^{-1}$, demonstrando uma maior atividade eletrocatalítica deste materiais para a oxidação do metanol e também um menor envenenamento da superfície dos intermetálicos pelos intermediários e produtos da reação de oxidação desse combustível comparado a Pt policristalina. Este melhor desempenho pode ser atribuído ao metal Sb que por apresentar característica oxofílica, pode estar formando mais facilmente espécies $\mathrm{OH}$ que promovem a oxidação de intermediários fortemente adsorvidos nos sítios ativos da superfície eletródica (Scachetti, 2007) e também uma alteração na configuração estrutural dos sítios superficiais e da densidade eletrônica superficial devido à distância aumentada dos sítios de Pt que pode vir a enfraquecer a adsorção da molécula de $\mathrm{CO}$ e influenciar na adsorção das moléculas de combustível sobre a superfície metálica dos catalisadores.

\subsubsection{Cronoamperometria}

A cronoamperometria é uma técnica de estado estacionário que mede a corrente elétrica em função do tempo quando se aplica um potencial. No presente caso, a atividade eletrocatalítica dos catalisadores dispersos foi estudada por cronoamperogramas, onde se aplicou um potencial de 0,6 $\mathrm{V} v$ s. EHMS. Os resultados com a técnica de cronoamperometria foram obtidos em $0,5 \mathrm{~mol} \mathrm{~L}^{-1}$ de $\mathrm{H}_{2} \mathrm{SO}_{4}$ e 0,5 mol L ${ }^{-1}$ de metanol, durante 600 segundos.

Na Figura 2 uma diminuição da corrente com o tempo é observada para todas as amostras. Logo após a aplicação do potencial, a corrente decresce rapidamente devido ao carregamento da dupla camada e a outros processos na superfície do eletrodo. Este comportamento esta de acordo com o comportamento já observado para oxidação de metanol em eletrodos casca-núcleo baseados em Pt. Os valores de pseudodensidades de corrente estacionária ao fim de $600 \mathrm{~s}$, para os eletrodos de $\mathrm{Pt}_{3} @ \mathrm{Sb} / \mathrm{C}, \mathrm{Pt}_{2} @ \mathrm{Sb} / \mathrm{C}, \mathrm{Sb} / \mathrm{C}$ e Pt/C polarizado em 0,6 V vs. EHMS foram: 9,020 A $(\mathrm{g} \mathrm{Pt})^{-1}, 0,1218 \mathrm{~A}(\mathrm{~g} \mathrm{Pt})^{-1}, 0,020 \mathrm{~A}(\mathrm{~g} \mathrm{Pt})^{-1}$ e $0,042 \mathrm{~A}(\mathrm{~g} \mathrm{Pt})^{-1}$, respectivamente. O aumento da 
atividade para eletro-oxidação de metanol da amostra $\mathrm{Pt}_{3} @ \mathrm{Sb} / \mathrm{C}$, pode ser resultante da satisfatória formação de uma estrutura casca-núcleo, e esta pode ser atribuída aos mecanismos geométrico e eletrônico, de forma a promover a oxidação de monóxido de carbono ou outros intermediários na superfície da platina.

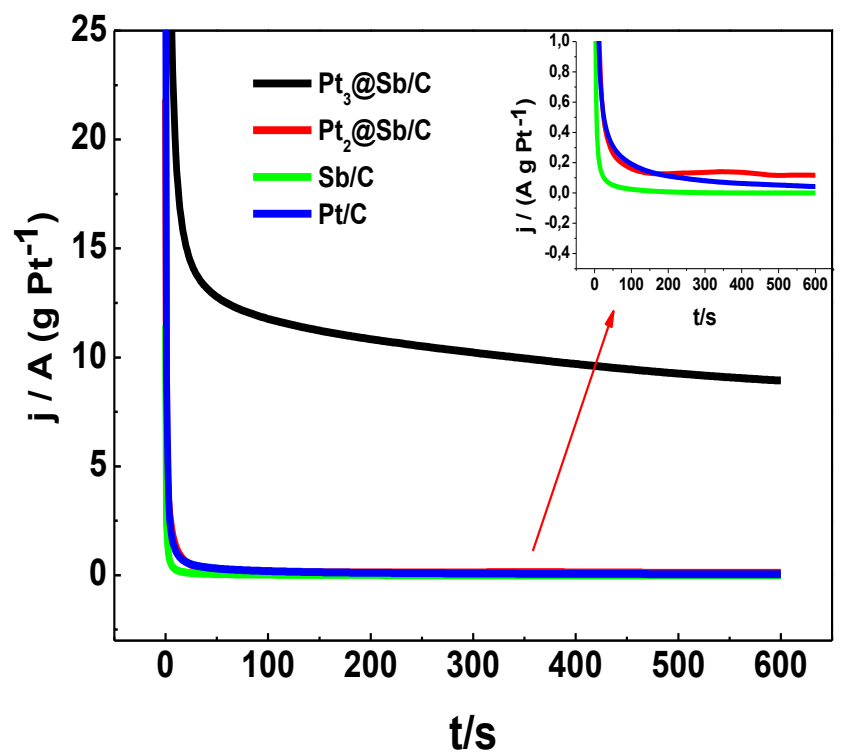

Figura 2 - Cronoamperogramas obtidos para os eletrocatalisadores $\mathrm{Pt}_{3} @ \mathrm{Sb} / \mathrm{C}, \mathrm{Pt}_{2} @ \mathrm{Sb} / \mathrm{C}, \mathrm{Sb} / \mathrm{C}$ e $\mathrm{Pt} / \mathrm{C}$ em solução aquosa de $0,5 \mathrm{~mol} \mathrm{~L}^{-1}$ de $\mathrm{H}_{2} \mathrm{SO}_{4}+0,5 \mathrm{~mol} \mathrm{~L}{ }^{-1}$ de metanol. Eletrodos polarizados a $0,6 \mathrm{~V}$.

\subsubsection{Curvas de polarização}

Para um melhor entendimento do desempenho catalítico de todos os materiais estudados para oxidação de metanol até o momento, foram realizadas curvas de polarização em estado quase estacionário, onde ocorre a diminuição de processos capacitivos e obtêm-se respostas apenas de correntes faradáicas nas condições apresentadas na Figura 3.

Pode-se observar na Figura 3 que os eletrocatalisadores $\mathrm{Pt}_{3} @ \mathrm{Sb} / \mathrm{C}$ e $\mathrm{Pt}_{2} @ \mathrm{Sb} / \mathrm{C}$ apresentaram uma melhor atividade catalítica para reação de eletro-oxidação de metanol tanto a elevados valores de potencial quanto a baixos potenciais (<0,55 V vs. EHMS). Comprovando assim que os materiais casca-núcleo apresentaram uma maior eficiência durante a atividade de oxidação do metanol quando comparado ao $\mathrm{Sb} / \mathrm{C}$ e a $\mathrm{Pt} / \mathrm{C}$. 


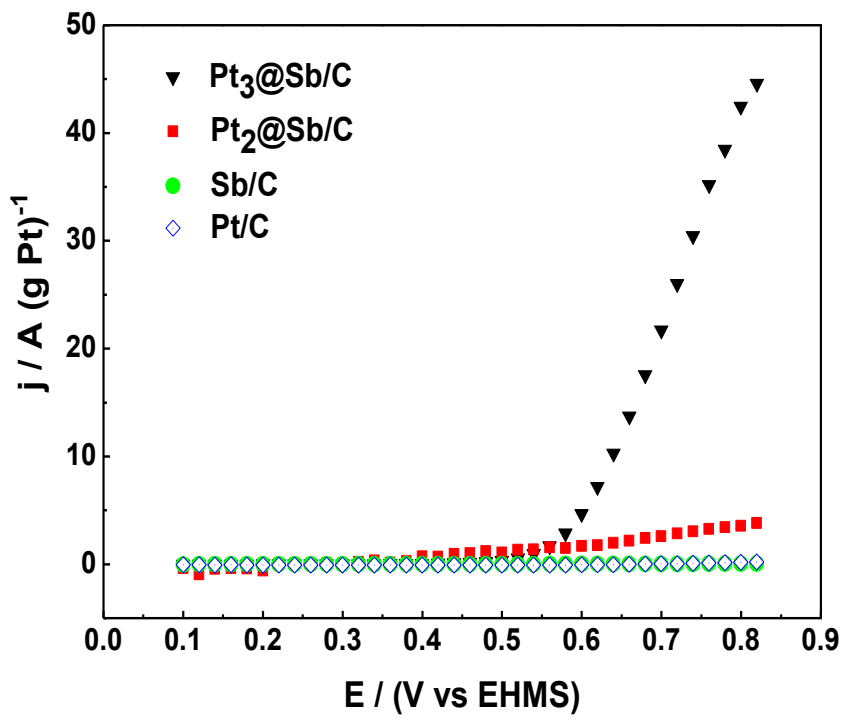

Figura 3- Curvas de polarização dos eletrocatalisadores $\mathrm{Pt}_{3} @ \mathrm{Sb} / \mathrm{C}, \mathrm{Pt}_{2} @ \mathrm{Sb} / \mathrm{C}, \mathrm{Sb} / \mathrm{C}$ e Pt/C em solução de $0,5 \mathrm{~mol} \mathrm{~L}^{-1} \mathrm{H}_{2} \mathrm{SO}_{4}+0,5 \mathrm{~mol} \mathrm{~L}^{-1}$ de metanol.

\section{CONCLUSÃO}

Os resultados obtidos neste trabalho indicam a viabilidade da proposta inicial, que é desenvolvimento de uma rota de síntese de nanocatalisadores casca-núcleo contendo platina e antimônio com atividades eletrocatalíticas satisfatórias para a oxidação de metanol em meio ácido. A metodologia proposta para a síntese dos nanomateriais $\mathrm{Pt}_{x} @ \mathrm{Sb}_{y} / \mathrm{C}$ mostrou-se eficiente. O método de redução sucessiva adaptado neste trabalho corresponde ao primeiro exemplo de síntese de nanoestruturas do tipo casca-núcleo contendo Pt e Sb.

\section{REFERENCIAS}

ANTONIASSI, B.S., Estudo da eletrocatálise das reações de oxidação de ácido fórmico e metanol sobre fases intermetálicas ordenadas $\mathrm{Pt}-\mathrm{M}(\mathrm{M}=\mathrm{Mn}, \mathrm{Mo}, \mathrm{Pb}, \mathrm{Sb}$ e $\mathrm{Sn})$. 2006. $140 \mathrm{f}$. Dissertação (Mestrado em Ciência e Tecnologia de Materiais) - Faculdade de Ciências, Universidade Estadual Paulista, Bauru, São Paulo, 2006.

DEBE, M. K. Review: Electrocatalyst approaches and challenges for automotive fuel cells, Nature, 486, p. 43-53, 2012.

FALIN, C.; SHYI-MIN, L.; YI-LIN, C. Renewable Energy in Taiwan: Its developing status and strategy, Energy, 32, p. 1634-1646, 2007.

GARCÍA-CONTRERAS, M. A.; FERNÁNDEZ-VALVERDE, S. M.; VARGAS-GARCÍA, J. R.; CORTÉS-JÁCOME, M. A.; TOLEDO-ANTONIO, J. A.; ÁNGELES-CHAVEZ, C. Pt, PtCo 
and PtNi electrocatalysts prepared by mechanical alloying for the oxygen reduction reaction in 0.5 M H2SO4, Int. J. Hydrogen Energy, v. 33, p. 6672-6680, 2008.

LEE, M. H.; DOO, J. S., Kinetics of oxygen reduction reaction on Corich Core-Ptrich Shell/C electrocatalysts, J. Power Sources, v. 188, p. 353-358, 2009.

MASSALSKI, T.B. Binary Alloy Phase Diagrams. The Materials InformationSociety. Ohio: ASM International: v. 03, 2 ed. 1990.

MOFFATT, W.G. Binary Phase Diagrams Handbook. New York: General Electric Co. 1976.

ROQUET, L., BELGSIR, E. M., LÉGER, J.-M., LAMY, C., Kinetics and mechanisms of the electrocatalytic oxidation of glycerol as investigated by chromatographic analysis of the reaction products: Potential and pH effects, Electrochim. Acta, v. 39, p. 2387-2394, 1994.

SALGADO, J. R. C. GONZALEZ, E. R. Correlação entre a atividade catalítica e o tamanho de partículas de Pt/C preparados por diferentes métodos, Eclética Química, v. 28, p. 77-85, 2003.

SCACHETTI, T. P. Estudo da Eletrocatálise da Reação de Oxidação de Etanol sobre Fases Intermetálicas Ordenadas Pt-M (M = Mn, Mo, Pb, Sb e Sn). 2007.100 f. Dissertacao (Programa de Pos-Graduacao em Ciencia e Tecnologia de Materiais). UNESP, Bauru, 2007.

TAMIZHMANI, G.; DODELET, J. P.; GUAY, D. Crystallite Size Effects of Carbon Supported Platinum on Oxygen Reduction in Liquid Acids, J. Electrochem. Soc., v. 143, p.1823, 1996.

ZHANG, J.; LIMA, F. H. B.; SHAO, M. H.; SASAKI, K.; WANG, J. X.; ADZIC, R. R. Platinum monolayer on nonnoble metal-noble metal core-shell nanoparticle electrocatalysts for O-2 reduction, J. Phys. Chem. B, v. 109, p. 22701-22704, 2005. 